\title{
HOW TO DISTIL WORDS AND OBTAIN CULTURE HISTORY ${ }^{*}$
}

\author{
JAN VANSINA \\ UNIVERSITY OF WISCONSIN-MADISON
}

Nearly every historian of early African history has recently encountered studies that use the history of words as a source for history more generally defined, an approach also known as words-and-things. Indeed, by now a more or less elaborate use of words-and-things has become fashionable, especially in the Anglophone literature. A number of short presentations of the overall principles underlying this approach have been published, but they all lack an extended discussion of the methodological issues involved. ${ }^{1}$ Perhaps this is the main reason why words-and- things analyses are almost never subjected to critical scrutiny, while the conclusions of studies based on them, however weak or strong they might be, tend to be accepted as gospel-a most unsatisfactory situation. Hence a book-length study of the methodology involved in the application of words-and-things should be very welcome.

As Klein-Arendt's book is devoted exclusively to this subject, it should fill the gap. Yet it will disorient most readers of this journal because K-A is not concerned with the solution of smaller- or large-scale problems of history as understood by such readers, but focuses on the epistemology of the central European school known as Kulturgeschichte (more or less "Culture History"), to which he subscribes and which is likely to be

\footnotetext{
*A review essay of Reinhard Klein-Arendt, Die traditionellen Eisenhandwerke der Savannen-Bantu. Eine sprachbistorische Rekonstruktion auf lexikalischer Grundlage (Frankfurt, 2004).

${ }^{1}$ E.g., David Schoenbrun, $A$ Green Place, a Good Place (Portsmouth NH, 1998), 6-12; Jan Vansina, Paths in the Rainforests (Madison 1990), 9-16, and the latest of several such pieces by Christopher Ehret, "Writing African History from Linguistic Evidence" in Writing African History, ed. John E. Philips (Rochester, 2005), 91-98.
}

History in Africa 33 (2006), 499-511 
largely unknown to most readers. ${ }^{2}$ Yet when the expression "words-andthings" was first coined in 1909. it was intended to be a tool to elucidate Kulturgeschichte. Indeed, the journal from which the label stems was called Wörter und Sachen. Kulturhistorische Zeitschrift für Sprach-und Sachforschung (Words and Things. a Journal of Culture History for Research in Languages and Things) and on its very first page Rudolf Meringer stated that "[l]inguistics is only' a portion of the science of culture ... We hold that the future of Kulturgeschichte resides in the union of the science of language with the science of things" in which "things" stood for what came to be better known as "culture traits." 3

Nevertheless, K-A's book remains the only work devoted to a full discussion of the methodology for words-and-things and, as such, is worthy of attention. Not only does K-A address these issues theoretically, but he both illustrates and substantiates his arguments by providing a fully developed case study intended to provide the proof of the theoretical pudding. Before we turn to a discussion of his methodological considerations, it may be helpful to dwell a bit on his choice of case-study because that is also a handy introduction into the epistemology of culture historians.

II

This case-study focuses on the history of ironworking among the Bantuspeaking savanna dwellers of east-central, eastern, and southern Africa. KA's reasons for choosing this case seem to be the following. Along with many other linguists, he holds (14) that the Bantu languages of these regions form one of the major genetic subdivisions of Bantu. Furthermore , along with his doctoral adviser W.J. Möhlig, but against the views of most linguists, he argues $(18-21,71-73)$ that these languages are the result of a series of overlapping linguistic "waves" or diffusions, each of which was accompanied by its own package of culture traits, and he seems to hold further that most of these diffusions resulted from separate migrations. In his vision, all the modern Bantu languages are the product of a

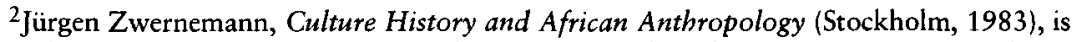
perhaps the best introduction to "Kulturgeschichte" for Africanists. Zwernemann shows that a number of scholars in Germany never wholly abandoned the fundamental theoretical tenets of the school. Indeed there has been a considerable revival of "Kulturgeschichte" during the last three or four decades under the influence of well-known scholars, of which the linguist Wilhelm J. Möhlig, Klein-Arendt's revered thesis director (7) is one.

${ }^{3}$ Rudolf Meringer, "Vorwort," Wörter und Sachen. Kulturhistorische Zeitschrift für Sprach-und Sachforschung 1/1(1909), as cited by Klaus Beyer, Pferd, Schwerter und Macht, Ein historisch-vergleichende Studie zur Kulturwortfeldern in den Oti-Volta Sprachen (Cologne, 1998), 14. 
series of such waves and their cultures the sum of the deposits of successive layers or strata of cultural elements. He plans to use the words-andthings approach in order to disentangle the various strata and thus to recover the history of "the" Savanna Bantu Iron Age culture. His case study about ironworking is only a first step towards that goal, for K-A wants further lexical studies of related domains, beginning with those that are closest to ironworking, namely (260), "iron products, house construction, agriculture, animal husbandry, hunting, war, medicine, the naming of groups, and other crafts such as woodworking, plaiting and ceramics" Doing this will lead to an all-encompassing account of the historical processes that created a reified entity known as "the" Savanna Bantu Iron culture.

After having stated his goals, K-A begins (25-40) the discussion of his research design in his second chapter. He rejects designs based on the use of linguistic tree-models because of their underlying assumption of monogenetic origin, as well as designs focusing on individual loanwords because they would only lead to piecemeal results. He concludes that only the particular dialectological approach advocated by Möhlig will do. ${ }^{4}$ Research projects should not be based on "basic words," defined as those that have the highest frequency of usage, but on those that are used far less often dubbed "culture words," even though he points out (27-38) that many (most?) of the latter, especially technical terms, are etymologically derived from basic words.

A valid project should be based on a cluster of words, but the cluster should not be justified by the argument that the words it includes share a single semantic field (Wortfeld), as others have often done, because the members of a single Wortfeld need not be mutually defined by each other, since such fields change over time, and since the history of each word in such a field can be different from that of the others. Still, because it would be impossible to study the many thousands of culture words all at once, one needs to choose (27-29) a cluster of words that constitutes a single fuzzy semantic set.

In the next chapter K-A sets up the design for his own project with regard to both area and choice of subject and vocabulary. First, a coherent geographical area must be set up (in his case eastern and southern Africa). Data must then be gathered from all the languages that are spoken within the chosen area, as is the practice in dialectological studies. No exceptions

\footnotetext{
${ }^{4}$ Yet Klaus Beyer, another culture historian, used the tree-model most efficiently in his exemplary and impressive word-and-things book Pferde, Schwerter und Macht about the horses, weaponry, and notions of power that accompanied the creation of large-scale polities in the central Gur-speaking regions.
} 
can be tolerated. As a corollary to the principle of closed areal unity, it follows that the distribution of any word found within the area should not be pursued beyond it.

With regard to his subject, K-A chooses (58) to focus on a subset of concepts expressed by "culture words," to wit, technical words relating to the physical activities involved in ironworking found in all the Bantu languages (but no others!) in eastern and southern Africa. Elsewhere he identifies one further subset of words, those that express a Leitbegriff or "leading concept." In contrast to other concepts and the words that express them, the semantic content of a leading concept is solely and unambiguously restricted to the subject studied (102). In his example, they are words that relate only to "ironworking" in contrast to others, including "iron" itself, which do not have such an exclusive semantic domain. Thus, with regard to forging, only "to forge" and "smith" are leading concepts, as are "to smelt" and "person who smelts" with regard to smelting. It follows that, whereas evidence from all other words need not always be linked to the spread of ironworking, evidence from leading concepts is necessarily and always linked to it.

The corpus of words for K-A's case study consists in large part, but not wholly, of technical terms since he also includes everyday words such as "fire," "charcoal," and even "iron" or "rust," which may behave in ways different from technical terms. And even though he identifies leading concepts, he actually does not privilege them in his interpretation of the evidence. His corpus does not constitute a single Wortfeld but it constitutes a single fuzzy set in which he distinguishes (60-61) five concentric levels that will become relevant once the time comes to draw historical conclusions. These levels are concepts relating to forging, smelting, both smelting and forging (e.g., "bellows"), general non-technical concepts (e.g,. "iron"), and very general concepts (e.g., "fire" or "ember"). In order to preserve the unity of this fuzzy set, K-A excluded "religious concepts" relating to ironworking. Although iron working includes a relatively large set of words compared to the vocabulary for other crafts, the advantages of choosing this topic are many. Ironworking has changed "the cultural life" (44) in the regions of Bantu settlement more than any other craft; its practice and its vocabulary have great time depth; and this vocabulary, he claims (43-44), has been both one of the most conservative and also one of the most innovative. He then justifies his choice of the savanna languages as opposed to those of the rainforests (including the westernmost savannas).

In the same chapter K-A goes on to discuss (51-52) his gathering of the words involved. Some of these he collected in the field himself, but most of them are drawn from existing lexicons identified in a bibliography 
arranged by language which he provides (277-98). Among the difficulties this procedure engenders, he highlights the unevenness of the data available for different concepts, the need to eliminate concepts that did not have a very wide distribution, and the fact that many concepts are rendered by words from everyday language (basic words!) rather than by technical terms. Vague glosses and European concepts that are not rendered by single words in the languages considered also raise problems (5457). K-A draws attention to the "provisional" exclusions that result from his choice of topic. He excludes (59) consideration of other metals and he artificially separates ironworking from the notion of "the culture of iron," simply because the vocabulary involved is far too large for a single study and moreover involves a discussion of "iron age."

Once the words were assembled, K-A arrayed them in sets sharing the same roots as found by the method of regular sound correspondences between the different languages, a list of which occurs in the work of Guthrie. ${ }^{5}$ The spatial distribution of the reflexes for each set were then plotted on two maps: one (set A) for each European concept, the other (set B) for the most common African words. All the sets, each accompanied by maps of their distributions, are published in a huge appendix (303-735). Each distribution corresponds to a diffusion and hence represents a hypothetical layer of culture. Hence it is necessary to order all of these distributions in sets of similar geometric form and spatial extent so as to uncover common patterns between them-patterns that express different cultural layers. This operation yields five such layers: three varieties of superregional, one regional, and one local layer.

Chapter 4 (74-102) deals with issues concerning the systematic interpretation of distributions. K-A uncovers two overall features of interest: the existence of regional areas whose languages share a particular technical vocabulary, and large-scale pathways of diffusion. Regional areas are determined by a set of continuous distributions that are partially congruent with each other. They exhibit a nuclear area, where all the forms involved overlap, and an outer ring in which only some of them occur. Such patterns indicate the regional development of an autonomous vocabulary. But since K-A focuses on large-scale diffusions, he does not pursue these regional phenomena any further (74-76).

The first step in analyzing diffusions is to find the direction of their flow. To do this K-A relies (76-92) on the semantic history of each reflex in a set of words sharing the same form rather than on the identification

${ }^{5}$ Malcolm Guthrie, Comparative Bantu (4 vols.: Farnborough 1971), 2:28-64. This inventory is rather incomplete and sometimes wholly unreliable. Actually, K-A must have relied in many cases on the "method of obvious similarity." 
of irregularities (skewing) in the form of the reflexes in such a set, which is the usual approach, but one that is often difficult to carry out for lack of the necessary linguistic information. K-A posits as an absolute rule that the meaning of a word always shifts over time from a general meaning to a more technical one and that word derivation in Bantu languages (usually deverbatives and/or shifts in classes) is normally quite regular and obvious. Shifts often occur in a chainlike fashion such as for example: lunga "to make a fire" > elungu "fire" > elungu "hearth"> ilungu "smelting furnace"> mwilungu "bloom" $(80,91)$. By plotting the meanings of the root involved on the distribution map, it becomes obvious that the diffusion must have begun in a place where both the verb "to make a fire" and its deverbative "fire" are attested, and that "bloom" originated in a place that also has "furnace." Once the etymology of a technical term has thus been traced back to a general meaning, one needs to trace the whole distribution of the word with the general meaning in order to find the place where both items overlap, because that is the place where the technical term was coined. But one still needs to identify formal skewing of the reflexes whenever the semantic approach allows for more than one place of origin and/or directions of spread-a situation that often occurs-so as to narrow down the number of places of possible origin (93-96).

Once the origins of various diffusions have been established, one groups words in sets that share the same region of origin, the same direction of diffusion, and the same destinations. By far the most efficient way to do this is to plot the distributions for each word on a map and to compare the resulting maps. However, all the words in a set need not have diffused at the same time (96-99). To demonstrate that they did, the areas of their distribution must be nearly congruent, and the geographic direction indicated by the chains of their semantic shifts must be identical. K-A further claims that the more words can be bundled together in such a fashion, the greater the probability that they are synchronic and constitute a bundle of culture traits that belong to the same layer or stratum of culture. Once such bundles are identified, their successive diffusions must be ordered (96-102) into a single relative chronology so as to obtain a complete culture history of the area studied. To achieve this, one compares the distributions of different bundles to identify spots where one set of distributions is interrupted by another cutting across it, since the bundle that cut across the path of the other one must have diffused later than the first one.

Once again, the more words are involved in each bundle, the higher the probability that the chronology is correct. Ultimately this procedure should allow one to establish the sequence of diffusion of all the bundles involved and to establish their relative chronology. Yet K-A warns us (101) that, despite the massive size of his database, his case study still does 
not provide a large enough number of diffusions and bundles to rule out chance altogether. He thinks that eventually it will be possible to compare his results, based on semantic shifts, to those of the approach developed by Möhlig, which relies on sound shifts, and to reach highly reliable conclusions when the results of both approaches agree. ${ }^{6}$

The long (102-253) fifth chapter that follows provides what should be the proof of the pudding: the full-scale application of the method to the case of ironworking. This leads to the identification of nine bundles of diffusions that can be seriated to yield a set of strata ranging from a preBantu layer to a twentieth-century one. While his two oldest "Bantu" layers correspond to strata identified by Möhlig, the following ones do not. Moreover K-A was unable to place the bundle of diffusions that relates to the Luba world in his chronological framework. His findings further include the identification of seven regions characterized by the use of a typical and partly exclusive vocabulary.

Despite these partial results, K-A declares victory at the outset (254) of his last chapter: his case study does demonstrate the success of his method. He follows this up with a wish list for future research: better transcribed data; more data, including a complete corpus of basic words; research into adjacent African language families that are not Bantu; research into domains complementary to that of ironworking proper and which will eventually document "large scale migrations of ethnic groups" (260). All this is to be accompanied by archeological, and especially by ethnological, research (264), as well as by studies of oral traditions. K-A ends with the renewed assertion that he has shown how to overcome the stagnation of Bantu historical linguistics. But much remains to be done since, in his words (267), "[ $\mathrm{t}]$ he final product has to be a precolonial migration and settlement history of the Bantu peoples, with the discriminative power to account for both the multitude and the complexity of the historical phenomena in the savanna."

\section{III}

My comments follow the order of the steps required for the application of this method, from the initial choice of the vocabulary and the area of research to the grouping of the related reflexes of a word and their mapping, the interpretation of each of these sets, the bundling of words with similar distributions, and, finally, the ordering of such bundles into a relative chronology as deduced from the geometry of their distributions.

${ }^{6}$ Möhlig's strata were published as "Stratification in the History of the Bantu Languages," Sprache und Geschichte in Afrika 3(1981), 251-316. His hypothetical succession of sound shifts has not convinced any other linguists. 
K-A's-or Möhlig's-stress on the dialectological approach-that is, the choice of an arbitrarily predetermined area and the need to obtain data for all the languages it contains-is a procedure that runs contrary to practically all other research designs. In practice, the historical problem to be studied always determines the design worked out by the researcher, including the choice of vocabulary and area. In many cases the choice of languages is determined by their assumed or proven common genetic ancestry, and the area covered is the one where such languages are spoken. K-A's insistence on the dialectological approach is disingenuous, since he starts with a genetic unit, his Savanna Bantu, which sets the limits of his area. Moreover, and contrary to the requirements of the strict dialectological approach, K-A does not include data from all the languages within the chosen area since he omits all non-Bantu-speaking enclaves within it.

In practice this procedure is not all that different from Klaus Beyer's choice of the central Gur languages and the area they occupy. Granted that convergence between the Gur languages has been much less pronounced than between the Savanna Bantu languages, there was a good reason for choosing a dialectological approach in the latter case. Nevertheless, a major weakness of this approach is its refusal to pursue attestations beyond the chosen area. for any of the forms studied. This violates the general rule that one must always pursue the distribution of the formal reflexes of a word wherever they are found and irrespective of the genetic affiliation of the languages in which they occur. As long as this is not done, the evidence remains incomplete and the consequences can be disastrous, as K-A's case-study shows. His dialectological approach prevented him from identifying the oldest words for "iron," "forging," "smith," and "sledgehammer" in his corpus and hence to identify the oldest spread of ironworking. ${ }^{7}$

With regard to the choice of vocabulary, one can accept K-A's rejection of the notion of a strict semantic field (Wortfeld). Nevertheless, all researchers, including $\mathrm{K}-\mathrm{A}$, choose a topic for study, and that topic is expressed by a single more or less fuzzy semantic domain, Potentially a major problem here is that K-A set up this semantic domain in terms of European concepts (see his map series A, which orders words according to European concepts), not African ones, In this case a problem is avoided because there exists nearly total congruence between the Bantu and European domains relating to the physical aspects of ironworking. But if K-A's chosen topic of study had focused on largely intangible concepts-such as

7I refrain here from specific comments on K-A's case-study of ironworking. See my study of ironworking in Bantu speaking Africa in this journal. 
"religion," for example-the results would be highly Eurocentric and nugatory. Because of this, the rule must be that words-and-things studies involving African languages should always be based on a collection of African terms that have been shown to be interconnected. Such interconnections will then constitute a fuzzy semantic field or, as in Beyer's Gur study, several fields associated with each other.

As K-A recommends, setting up series of reflexes should be done by establishing sound correspondences, but even so, in practice one begins by picking out look-alikes in order to set up such correspondences in the first place. Given the number of languages involved and our imperfect knowledge of the sound correspondences, K-A certainly grouped his reflexes in large part by their overall similarity. Actually, he did not pay enough attention to the formal features of the words he examined and hence he underestimated the role of formal criteria in determining both whether words are loanwords or not, and in establishing the direction of their eventual diffusion. He is attentive to the consonants in the Bantu roots he studies, but he neglects to consider differences between second and thirddegree vowels, and wholly ignores tone, vowel length, and the quality of final vowels. His choice of lexical material confirms this. For Bushong he chose a large dictionary that does not indicate tone, vowel length, or the difference between vowels of the second and third degree, while neglecting a vocabulary that does include all these features. This matters when one realizes that some forms cited in the Bushong dictionary might confuse up to eight different words.

Or again K-A chose an early Rundi dictionary that does not record tone by an author whose understanding of Rundi grammar was limited, rather than a much fuller dictionary with tone and with lists of lexical derivations from common roots. Hence his references to Alt-Kirundi (73, 250 ) are totally spurious. In his case study he rarely made use of formal criteria and never found phonological filters, that is, situations in which formal change from language $A$ to language $B$ explain the reflexes, while a change from B to A would be impossible. Granted that formal criteria are often absent or hard to find in the case of the Bantu languages he studied, there were still quite a number of formal indications for skewing (and hence indication of borrowing) to be found in the sets K-A assembled. The contrast between this study and Beyer's research is striking, although to be fair, this resulted in part from the much greater divergences between the Gur languages. Nevertheless, because of his use of formal criteria, Beyer's procedures and findings tend to be far more convincing than most of $\mathrm{K}$ A's results.

On the other hand K-A's systematic search for etymologies and his use of semantic shifts to establish the direction of diffusions is very welcome. 
This constitutes a significant advance in method that contributes much to the relative success of his case study. But, even so, there are a few reservations. Thus a semantic shift does not always run from a more general to a more technical meaning. Thus K-A derives Swahili nyundo "sledgehammer" $(89,124,247)$ from a verb -unda "to build," but while nyundo is a proto-Sabaki reflex, -unda is a Swahili innovation. ${ }^{8}$ So if the two Swahili words are linked, the shift went from "sledgehammer" > "to build" and not the reverse. In deriving the verb Swahili-speakers apparently interpreted the initial $n y$ - of the noun as a prefix of classes $9 / 10$, and thus produced the skewed form -unda, a point that K-A would have found by paying closer attention to formal clues.

One must also reject K-A's rule that when he could not find an etymology for a word in a Bantu language within his area, it had to be of extraBantu origin. This rule forgets derivations from onomatopoeia, something that actually accounts best for the two most widespread words for "bellows" and "to blow the bellows" in his area. It also underestimates the possibility that a less obvious Bantu etymology may exist, whether within the chosen area or outside it. Indeed, unless and until a derivation from a non-Bantu language has actually been proven, it can only be assumed on the evidence of skewed forms, and not merely because an etymology cannot be found. Thus using formal clues Beyer $(116-18,141)$ is able to show that nàaba "chief" in Central Gur is a loanword. He suspects it is a derivation from Arabic na'ib, "deputy representative," but he did not find corresponding forms in either Songhay or Hausa, the likely intermediary languages, Hence for the moment the etymology of nàabá must remain unknown.

The stress on semantics, welcome as it is, can also lead to anachronisms because meanings are documented by ethnographic observation. Unfortunately, K-A does not discuss this. For him "Ethnologie" is apparently an unproblematic endeavor, but it ought not to be. He leaves the impression that ethnology refers to recent observations that record the timeless presence of a meaning rather than documenting a meaning that is the outcome of a preceding historical process and is valid only for the date of observation. Hence K-A seems to retroject a contemporary meaning directly into that distant past when the word that designates it at present began to diffuse. without accounting for possible later changes of meaning. If he had raised the issue, he could have shown to what extent his use of etymologies to construct semantic chains can actually take semantic change within each language into account.

${ }^{8}$ Derek Nurse and Thomas Hinnebusch, Swabili and Sabaki (Berkeley, 1993), 644. 
The next steps of his procedure, namely, the recognition of bundles of words and the demonstration of the synchronicity of all the words in such a bundle are often far more controversial than the preceding ones. In practice it is rare for the distributions of different words to be congruent enough to set up a bundle of words. Even then, absolute congruence between such distributions is practically unheard of. Still, bundles can be accepted both when the word distributions are largely congruent and when the words involved can be shown to share the same general origin. Even so, how synchronic are these distributions? A dozen or more words relating to millet, sorghum, finger millet, and their cultivation techniques all diffused from East Central into West Central Africa. They form a bundle and they relate to a single technological complex. Yet not all of them are synchronic since the diffusion of "finger millet" is suspected to have occurred some 900 years after that of the others. ${ }^{9}$ In K-A's realm three words relating to ironworking-boolo, "iron," -túd- "to forge," and the derived -túdi 1/2 "smith," and (j)undo 9/10, "sledgehammer," all have comparable (but not really congruent) distributions and all originate on the Nigerian plateau or Adamawa. Is it meaningful to bundle them together? Is it not more instructive to stress the differences in distributions and the high probability that they were not synchronic?

Synchronicity must be proven. When there are no archeological indicators, K-A's procedure to achieve this by deriving a sequence between diffusions from the intersections of their distributions is theoretically sound, and it is not rare to find such intersections between distributions of individual words. But it is quite uncommon to find the same intersection between the distributions for all the words in one bundle and those belonging to a second bundle. Thus the spatial distribution of boolo, "iron," has been crosscut quite often, but always in different places from those of -túd- or -(j)undo, and usually those two have not been intersected by others in the same places either. This situation seems to be the result of far more frequent substitutions of new words for "iron" than for "forging" or for "sledgehammer." Such examples forcefully underline the truth of the saying that each word has its own history. In practice then, the chances are that different researchers studying the same corpus of data will construct different bundles; different sequences, and different culture histories.

In general, cultural historians including K-A envision all culture change as occurring in spurts and as originating from outside of the region they are studying. Hence for them words-and-things must always lead to the discovery of a succession of synchronic diffusions from outside into the

9Jan Vansina, How Societies are Born (Madison, 2004), 74-81. 
region studied. These diffusions then correspond to different layers or strata of "culture" that eventually will encompass the whole vocabulary and the sum total of all the traits that make up a culture. This vision has often been, and must be, rejected on many grounds. A few among these are that it reifies culture, that culture cannot be divided into discrete and timeless traits (each represented by a particular word) of which it is the sum, and that internally-generated change in a given society becomes impossible. Such propositions all run counter to the experience and the intuition of all historians.

In order to arrive at this common cultural historical vision, K-A has been obliged to dismiss or minimize regional characteristic vocabularies, which can only be a product of local or regional internal innovations. In doing so he does not merely privilege external innovation over internal developments, but actually erases the latter. Once internal innovations are taken into account, it becomes evident that some historical change occurs continuously from generation to generation and that the vision of cultural strata laid down by periodic irruptions from the outside must be abandoned in favor of one that assumes that continual smaller changes were taking place most of the time, but that this process was interrupted once in a while by periods of major upheavals. The arrival of ironworking certainly was such a period. Hence sometimes bundles of words do relate to changes of great import, such as the introduction of cereal agriculture to west-central Africa, but in most cases words-and-things provides evidence for hundreds of piecemeal, but constant, small changes, generated either internally within a single society or as products of the mutual interaction between neighboring societies.

\section{IV}

When readers want to check the reliability of particular studies of wordsand-things, they need to know the place of the languages studied in a genetic tree of languages, and they need a list of the sources from which the words are drawn as well as a list of the reflexes on which the study is based, preferably with maps showing their distribution. Very few works present all this information. Beyer does it and K-A does it even better. He deserves praise for this and those parts of his work will have lasting value as a tool of reference. Most of this information is contained in the huge appendix labeled "Kartenteil." This includes two sets of distribution maps, each accompanied by a full listing of the reflexes mapped-i.e., all the raw data he used for his case study. The dictionaries and vocabularies from which most of the reflexes cited are drawn are provided in part 1 (278-98) while elsewhere (51-52) he also provides a list of the languages 
in which he gathered the reflexes himself. The first set of maps, those labeled A, provides distributions by concepts in European languages such as "anvil" or "drill" (315-466), while the second one labeled B (467-735) is a series of African words. K-A thoughtfully provides a list of the languages used in the study (306-15) as well as a table of contents for the concepts presented in part A (315-16), but he neglects to provide a similar table of contents for the words that appear in part B, an omission that imposes a serious handicap for users of that part. It is unfortunate, because part $B$ is precisely the one most readers will want to use, since the African words, and not the European concepts, are the genuine sources on which all the rest is built. One also regrets the absence of a general index, so that those who want to consult the book about one or another specific point of method, for example his concept of "Leitbegriff," will have a hard time finding the passages they require.

K-A's book is a valuable, if ponderous, detailed introduction to major issues of method concerning the use of words-and-things. He presents his case study about ironworking in an exemplary fashion, but his claim that it proves his theoretical pudding ring hollow. It fails to do that in part because K-A did not follow his own prescriptions faithfully enough, in part because he did not see the necessity to pursue all the reflexes of any examined form wherever they were to be found, and in part because he underestimated the need to pay greater attention to issues of word form. But on his own terms he failed mainly because he could not set up synchronic bundles of words that are convincing, let alone order them chronologically. Nevertheless, readers of this journal should take account of this book because it raises significant issues of method and because it offers a large amount of data about ironworking accompanied by complete information that is accessible to scholars with even a rudimentary knowledge of German (except for the interpretations of his distributions embedded in his fifth chapter, 102-247). Moreover, this is a book that will be indispensable to scholars interested in the renewed vogue of culture-historical schools. 


\section{AFRICAN STUDIES ASSOCIATION DEADLINES 2006}

Materials must be postmarked on or before the deadline.

If the date falls on a holiday or a weekend, the materials are due the following business day.

\begin{tabular}{|c|c|c|}
\hline \multirow[t]{2}{*}{ January } & 1 & Conover-Porter Prize nominations are due (in even-numbered years). \\
\hline & 15 & Graduate Student Paper Prize deadline. \\
\hline \multirow[t]{2}{*}{ February } & 1 & African Studies Review deadline for ads for the April issue. \\
\hline & 15 & Distinguished Africanist Award nomination packets are due. \\
\hline \multirow[t]{2}{*}{ March } & 1 & ASA News deadline for ads for the April issue. \\
\hline & 15 & $\begin{array}{l}\text { Annual Meeting Proposals are due. Letters of Invitation should be requested at this time. } \\
\text { Coordinate Organizations } \\
\text { - Update address and contact person information. } \\
\text { - Meeting requests are due. All requests received after March } 15^{\text {th }} \text { will incur a } \$ 25 \text { administrative fee and } \\
\text { the meeting may not appear in the Annual Meeting Preliminary Program. } \\
\text { Proposed Panels and Roundtables are due. } \\
\text { International Visitor Award applications are due. International Visitor Award applicants must also submit } \\
\text { Annual Meeting proposals by March } 15 \text {. } \\
\text { Membership Deadlines. Individuals who join/renew after this date risk not receiving maximum } \\
\text { membership bentefits. }\end{array}$ \\
\hline May & 1 & $\begin{array}{l}\text { Melville J. Herskovits Award nominations are due. } \\
\text { Paul Hair Prize nominations are due (in odd-numbered years). }\end{array}$ \\
\hline June & 1 & $\begin{array}{l}\text { ASA News deadline for ads for the July issue. } \\
\text { Book Donation Award applications are due. }\end{array}$ \\
\hline July & 1 & $\begin{array}{l}\text { African Studies Review deadline for ads for the September issue. } \\
\text { History in Africa deadline for ads for the September issue. }\end{array}$ \\
\hline \multirow[t]{2}{*}{ September } & 1 & $\begin{array}{l}\text { Annual Meeting Final Program deadline for ads. } \\
\text { Deadline to cast a vote for the ASA Officers and Board of Directors Elections. }\end{array}$ \\
\hline & 30 & $\begin{array}{l}\text { Annual Meeting pre-registration deadline. } \\
\text { Letters of Invitation Requests are due. Requests received after this date will incur a } \$ 25 \text { administrative fee. }\end{array}$ \\
\hline October & 1 & $\begin{array}{l}\text { African Studies Review deadline for ads for the December issue. } \\
\text { Coordinate Organizations } \\
\text { - Annual Reports are due (maximum of } 5 \text { pages). }\end{array}$ \\
\hline December & 1 & ASA News deadline for ads for the January issue. \\
\hline
\end{tabular}

